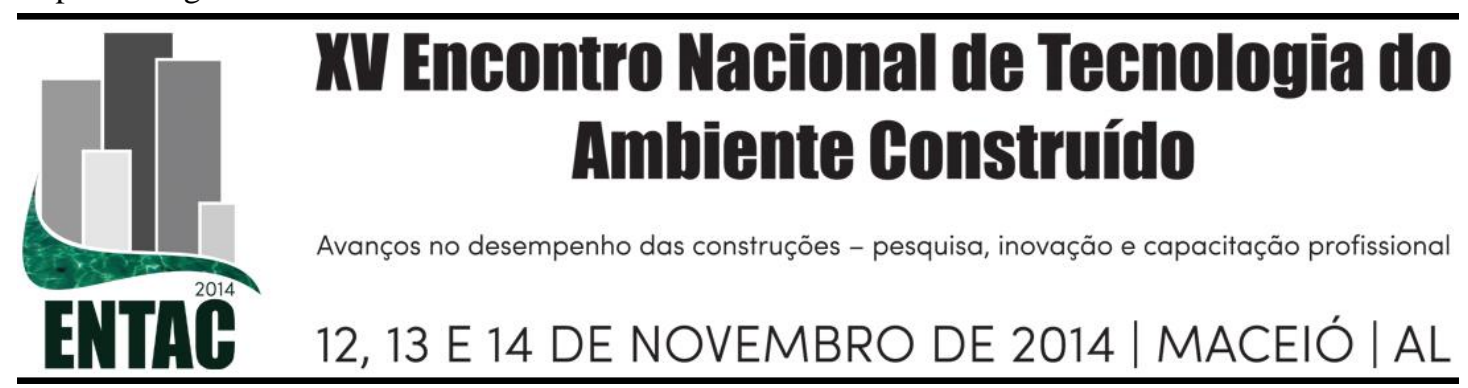

\title{
UTILIZAÇÃO DE FIBRAS DE CELULOSE NA COMPOSIÇÃO DE TIJOLOS DE ADOBES
}

\author{
SILVA, Fábia (1); BARROS, Bruna (2);
}

(1) UFAL, e-mail: engenhariacivil.fabia@gmail.com (2)UFRGS, e-mail: brunarb@gmail.com

\begin{abstract}
RESUMO
A indústria de celulose e papel é tradicionalmente avaliada como uma alta fonte de impactos ambientais negativos. Quanto à reciclagem desse componente, problemas ambientais continuam sendo gerados, pela utilização massiva de água e energia, e emissão de gases poluentes. Baseando-se nisto, o presente trabalho busca apresentar uma alternativa de emprego de resíduos de papelão a um dos principais componentes da construção civil. Trata-se da incorporação de fibras de celulose em tijolos de adobe naturais, os quais exigem baixo consumo de água, menores quantidades de solo e não necessitam de queima no processo de fabricação. Além da minimização de danos no meio ambiente, também possibilitam a redução do custo em comparação aos tijolos convencionais, uma vez que não é necessária a incorporação de cimento para estabilização dos materiais e, no que se refere à polpa do papelão, não necessita de grandes máquinas para obtê-la, proporcionando um processo limpo, rápido e de baixo custo, o que traz possibilidades de uso em habitações de interesse social. Nestes termos, para a realização deste trabalho, efetuaram-se pesquisas bibliográfica e experimental, com a confecção e análise de protótipos. Para a composição dos tijolos, foram utilizados solo, papelão triturado e água, moldados em uma forma de madeira. Assim sendo, a relevância deste trabalho encontra-se na ampliação do debate acerca de inovações tecnológicas na indústria da construção civil que desenvolvam materiais de baixo custo e reduzido impacto ambiental, trazendo alternativas para habitações sociais e aproveitando resíduos sólidos.
\end{abstract}

Palavras-chave: Indústria da celulose; resíduos; tijolos com fibras; habitações de interesse social.

\begin{abstract}
The pulp and paper industry is traditionally valued as a source of negative environmental impacts. As for this component recycling, environmental problems are continuously due to the massive use of water and energy, and greenhouse gas emissions. Based on this, this paper presents an alternative employment of cardboard waste to one of the main components of civil construction. This is the incorporation of cellulose fibers of natural adobe bricks, which inrequire low water consumption, smaller quantity of soil and require no firing the manufacturing process. Beyond minimizing damage to the environment, it also allows a reduction in the cost compared to conventional bricks, since it is not necessary to incorporate the cement for stabilization of the material and, as regards the pulp cardboard, does not require large machines to get it, providing a clean, fast and low cost, which brings possibilities of use in social housing. Accordingly, for this work, be effected experimental research, with the production and analysis of prototypes. To make up the bricks, there were soil, shredded cardboard and water, molded into a shape of wood. In preliminary results when compared with conventional ceramic blocks, we obtained performance above what the standard specifies for these types of blocks. Therefore, the relevance of this work lies in extending the debate on technological innovations in the construction industry to develop the of alternative material slow cost and low environmental impact, with alternative, which absorb seek solid waste, to minimize costs and environmental impacts.
\end{abstract}

Keywords: Cellulose industry; Waste; Bricks with fibers; Social housing. 


\section{INTRODUÇÃO}

A industrialização e o intenso avanço da tecnologia na produção de novos materiais impulsionaram a geração de resíduos sólidos, emissão de poluentes e alto consumo dos recursos naturais.

Esses materiais são importantes e trazem benefícios sociais para o Brasil, pois representam 5,4\% do PIB (JOHN, 2010 apud LCA CONSULTORES, 2005). Contudo, a investigação de um novo padrão de desenvolvimento que seja sustentável, socialmente mais justo e economicamente viável torna-se necessária (JOHN, 2010).

Assim, neste trabalho, serão abordados os resíduos de papel, os quais representam $38 \%$ do peso do lixo, mas em termos de volume esse valor aumenta consideravelmente (PÓLIS, 1998). A indústria de celulose e papel é tradicionalmente avaliada como uma alta fonte de impactos ambientais negativos no ar, solo e recursos hídricos, uma vez que utiliza produtos altamente químicos, consome grande volume de recursos naturais, forma o deserto verde capaz de secar rios e outras fontes hídricas, e contribui para a desertificação do solo. Quanto à reciclagem desse componente, problemas ambientais continuam sendo gerados, pela utilização massiva de água e energia, e emissão de gases poluentes.

Com base nessa realidade, o presente estudo apresenta uma alternativa de emprego de resíduos de papelão a um dos principais componentes da construção civil. Trata-se da incorporação de fibras de celulose em tijolos de adobe naturais, os quais exigem baixo consumo de água, menor quantidade de solo e não necessitam de queima no processo de fabricação. Além da minimização de danos ambientais, também possibilitam a redução do custo em comparação aos tijolos convencionais, uma vez que não é necessária a incorporação de cimento para estabilização dos materiais. No que se refere à polpa do papelão, não necessita de grandes máquinas para obtê-la, proporcionando um processo limpo, rápido e de baixo custo, o que traz possibilidades de uso em habitações de interesse social (HIS).

Assim sendo, a relevância deste trabalho encontra-se na ampliação do debate acerca de inovações tecnológicas na indústria da construção civil, a partir do desenvolvimento de materiais de baixo custo e reduzido impacto ambiental, trazendo alternativas para HIS e aproveitando resíduos sólidos urbanos.

\section{A INDÚSTRIA DA CELULOSE E OS IMPACTOS AMBIENTAIS}

Atualmente, o Brasil ocupa o quarto lugar na produção mundial de celulose. De acordo com dados da Associação Brasileira de Celulose e Papel (Bracelpa), o país alçou um crescimento médio de $7,1 \%$ na produção de 1970 a 2012. Contudo, no período de 1990 a 2008, houve um crescimento de $16 \%$ da produção média anual e, de 2008 a 2012, essa produção se manteve estável (BRACELPA, 2014).

No entanto, o elevado consumo de papel e a maior parte produzida com procedimentos insustentáveis têm gerado problemas socioambientais, conforme será exposto nos próximos parágrafos.

Os impactos da produção de papel são elevados e, por isso, há anos a Europa levou suas fábricas para os países em desenvolvimento, onde as leis ambientais são frágeis, e há carência por posto de trabalho e obrigação de originar divisas (IDEC, 2006).

Na produção do papel, são necessárias de 2 a 3 toneladas de cavacos para produzir uma tonelada de papel, 100 mil litros de água por tonelada e muita energia, o que coloca esse 
tipo de indústria no quinto lugar na lista das indústrias que mais consomem energia (ibid.).

O processo kraft é um dos principais na indústria, utilizando-se de uma série de insumos químicos e aditivos, onde muitos deles possuem elevado potencial de danos à saúde e ao ambiente. Entre os insumos mais utilizados, podem ser mencionados os compostos de cloro, enxofre e soda cáustica (ALMEIDA, 2013). Esse processo é um dos mais danosos à saúde humana e, quando concluído, é liberado um efluente denominado licor negro que contêm compostos tóxicos de enxofre que são cancerígenos.

No que concerne à reciclagem, atualmente, no Brasil, apenas $37 \%$ do papel confeccionado é direcionado para a reciclagem. No mais, de todo o papel recolhido para reciclagem, $80 \%$ se destinam à confecção de embalagens, $18 \%$ para papéis sanitários e somente $2 \%$ para impressão (FERRAZ, 2010). Entretanto, um mito bastante conhecido é a de que a reciclagem do papel salva as florestas e preserva os recursos naturais, mas na realidade não é bem isso que acontece. Isso porque o gasto de energia no procedimento de reciclagem do papel pode ser maior que o utilizado no processo normal de produção do papel. Em adição, outro ponto observado na reciclagem é que se consome muita água e, caso não seja tomado os devidos cuidados, esta água pode se tornar um líquido altamente contaminante (WEBRESOL, 2009 apud BULLETIN, 2003).

Assim, o desafio é acrescer a produção e arquitetar um mercado mais concorrente para os materiais reciclados que envolvam a diminuição de impactos ambientais negativos em suas produções. Para tanto, a Lei $n^{\circ} 12.305 / 10$, que institui a Política Nacional de Resíduos Sólidos (PNRS), estabelece princípios, objetivos, diretrizes, metas e ações importantes para os diversos tipos de resíduos gerados, alternativas de gestão e gerenciamento, contribuindo com projetos e ações de reciclagem (BRASIL, 2010).

\section{TERRA CRUA, ADOBES E AS FIBRAS}

Com o advento dos materiais industrializados, o tijolo de terra crua foi sendo esquecido como um material de construção, porém, mesmo assim, ainda hoje apresenta importância significativa à população. Nos países asiáticos, africanos e do oriente médio, conforme Figura 1, existem cidades edificadas com esse material, comprovando sua durabilidade (BARBOSA; GHAVAMI, 2010).

\section{Figura 1 - Cidades construídas em terra crua - Irã}
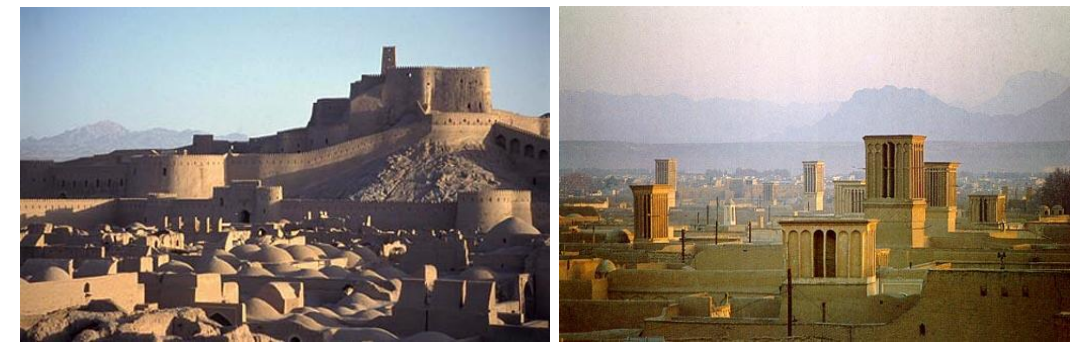

Fonte: IBRACON (2010)

Cerca de $30 \%$ da população mundial vive em edificações de terra. Ademais, cerca de $50 \%$ da população dos países em desenvolvimento, incluindo também a população rural e pelo menos $20 \%$ da população urbana e suburbana, vive em casas de terra (VARUM et al, 2008). 
No Cenário brasileiro, as construções com terra crua foram trazidas pelos portugueses. Ademais, a maioria das construções que estão espalhadas no país foi edificada com terra crua. Atualmente, em Minas Gerais, existem diversas construções que comprovam o bom uso desse material. A Figura 2 ilustra o exposto.

\section{Figura 2 - Construções coloniais de terra crua - MG}

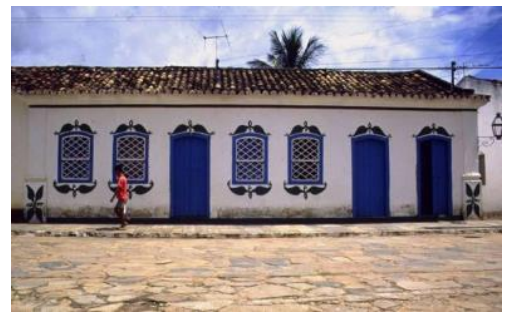

Fonte: IBRACON (2010)

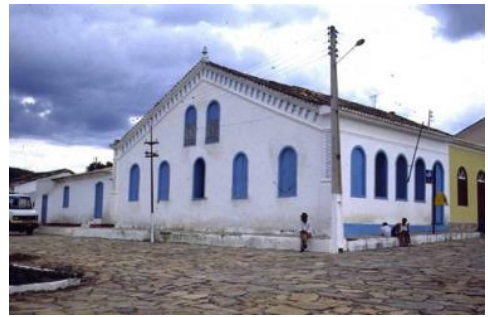

No trabalho de Bouth (1989), apud Souza Santos (2005), adobe é uma palavra de origem espanhola empregada no sudoeste dos Estados Unidos que caracteriza argilas adaptadas à confecção do tijolo cru, seco ao ar livre.

$\mathrm{O}$ adobe pode ser confeccionado de diversas maneiras, empregando em sua fabricação algumas fibras, como a de coco, feno, palhas secas, entre outras. Esses tijolos apresentam praticamente nulos o consumo de energia para sua produção e ainda, configuram-se como excelentes isolantes térmico e acústico, principalmente quando comparados ao cimento e o aço.

Os estudos sobre a utilização de fibras naturais nos tijolos de adobe têm conferido ao compósito maior resistência, no que se refere à compressão e a fissuras. No trabalho de Senhoras (2003), abordaram-se algumas experiências realizadas com a utilização da fibra de coco em materiais construtivos. Nele, afirma-se que materiais reforçados com fibras naturais são boas alternativas à construção civil, quando comparados a materiais que utilizam fibras sintéticas, a exemplo das fibras de vidro. As fibras naturais conferem propriedades importantes nos materiais que as recebem, como melhor rigidez, maior resistência ao impacto, e isolamento térmico e acústico.

Ghavami et al (1996), em seu trabalho sobre o comportamento dos solos reforçados com fibras naturais, enfatizam que uma das principais características das fibras de sisal é o reforço nas matrizes de solos, evitando rachaduras e trincas. Essas fibras evitam fissuras por adesão ou ligação ao solo.

Entre tantas outras vantagens, Izquierdo (2011) aponta a abundância dessa fibra no Brasil, uma vez que este é o maior produtor de sisal do mundo, sendo $80 \%$ das plantações no estado da Bahia.

No trabalho de Achenza e Fenu (2006) foram analisadas as dificuldades de preparar tijolos de adobe para construção de terra com menos erosão. Nesse contexto, testaram amostras de barro estabilizadas com adição de fibras vegetais, com um composto de polímeros naturais e diferentes amostras estabilizadas exclusivamente com fibras. Logo, observaram que a estabilização do solo com a fibra e o polímero proporcionam características importantes no que se refere à ação da água e ao aumento de resistência à compressão. 


\section{CONFECÇÃO DE ADOBES COM ADIÇÃO DE FIBRA DE PAPELÃO}

Com base na literatura, no que se refere aos tijolos de adobes e fibras, estudou-se neste trabalho a possibilidade de confeccionar tijolos de adobes moldados à mão com a adição de fibras de papelão, tomando como referência a pesquisa de Busson (2009), que utilizou fibras de celulose provenientes de sacos de cimento para fabricar blocos de terra compactados (Kraftterra).

A partir do referido estudo, analisou-se o processo de preparo das fibras dos sacos de cimentos e adequou-se o mesmo procedimento ao preparo das fibras do papelão, para uma posterior mistura nos adobes, com o intuito de obter um material de boa qualidade, baixo custo, fácil manuseio e baixo impacto ambiental.

\subsection{Materiais e métodos}

O primeiro passo no preparo dos materiais para a confecção do tijolo de adobe com fibras de celulose consistiu-se na separação e limpeza do papelão, no qual podem ser usadas caixas de papelão ou outros tipos de papéis, a exemplo de folhas de A4 que não servem mais para rascunho.

Deve-se ter o cuidado de observar nas caixas se elas contêm algum tipo de grampo, pois estes poderão prejudicar as hélices do liquidificador no processo de moagem e, ainda, devem ser retiradas fitas adesivas utilizadas para fechar as caixas. Esse tipo de plástico não se desintegra facilmente como o papel, prejudicando a qualidade das fibras.

Após essa seleção, realizou-se o corte das caixas com o auxílio das mãos. Cortaram-se pedaços com tamanho aproximadamente de 3 a $6 \mathrm{~cm}$, pedaços bem pequenos, posto que o liquidificador utilizado para moer as fibras foi um doméstico com capacidade de 1,5 L. Em seguida, adicionou-se água até que as fibras ficassem totalmente submersas (Figura 3a). Passadas 24h, o papelão amoleceu, podendo assim, ser disperso para obtenção da polpa. Na sequência, peneirou-se (Figuras 3b e 3c).

\section{Figura 3 - (a) Papelão de molho (b) Polpa na peneira; (c) Fibras de papelão}

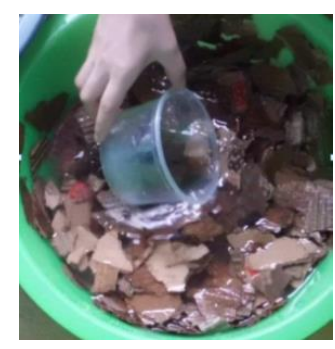

(a)

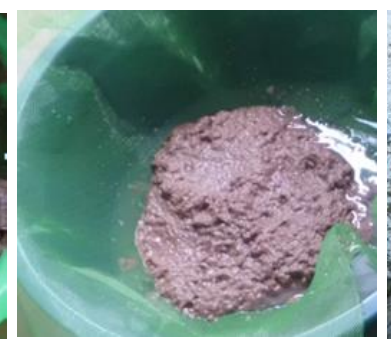

(b)

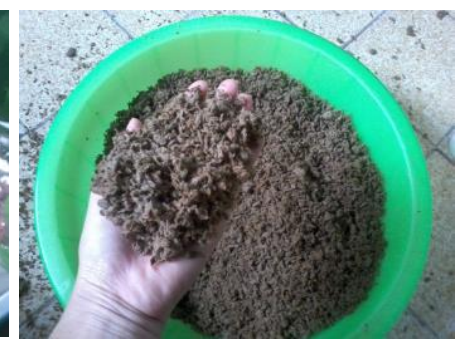

(c)

Fonte: Os autores (2013)

\subsection{Escolha do solo}

O solo adequado para a produção do adobe não pode estar molhado e não pode conter matéria orgânica, porquanto afeta a coesão das partículas da mistura e, ainda, não deve ter raízes, torrões, pedras ou qualquer outro material que venha a comprometer o adobe. No mais, uma das características importantes no preparo do solo é a granulometria, visto que o solo adequado para o adobe deve ter aproximadamente $60 \%$ de areia e $40 \%$ de argila (SÉRIE PRODUTOR RURAL, 1998). 
Para definir essas quantidades, podem ser feitas análises em laboratório ou realizar o teste do vidro, que, segundo Neves et al (2005), fundamenta-se na sedimentação diferenciada dos constituintes da terra (Figura 4a). Ela consiste em colocar uma pequena quantidade do solo em um recipiente de vidro transparente e, em seguida, adiciona-se água, cerca de $2 / 3$ da altura do recipiente e acrescenta-se uma pitada de sal. Esse irá agir como defloculante das partículas, entretanto se utilizado em quantidades maiores pode atuar de forma oposta (Figura $4 b$ ).

Figura 4 - (a) Amostra do solo agitada; (b) Separação do solo por sedimentação

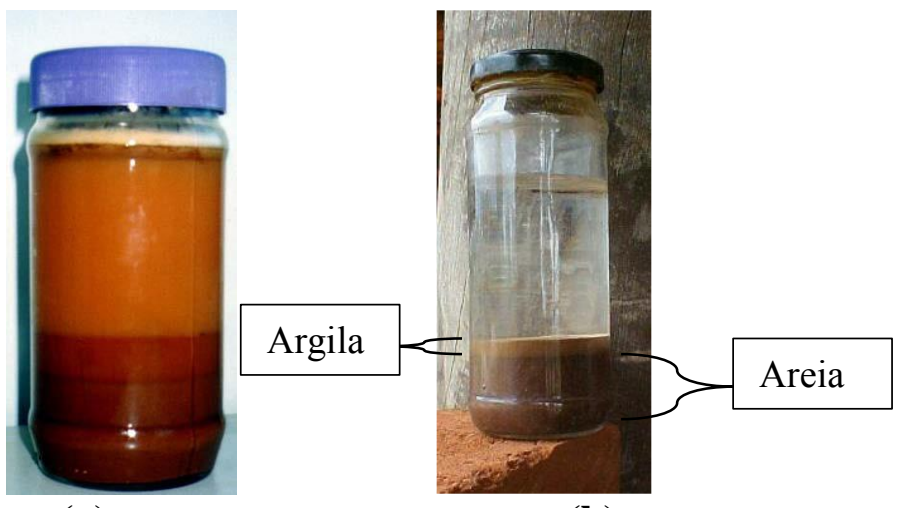

(a)

(b)

Fonte: Adaptado de Neves e Faria (2005)

O solo utilizado na pesquisa foi retirado das imediações da cidade de água Branca- AL (Figura 5a), que faz divisa com Delmiro Gouveia-AL, localidade em que o presente estudo foi realizado. Em Delmiro Gouveia, o solo é muito arenoso e com a presença de pedras, ao passo que em Água Branca, por situar-se em uma serra, a presença de pedras é bem menor. Conquanto, o solo proveniente da cidade citada era muito argiloso, isso ficou evidente com o teste do vidro (Figura 5b), e para corrigi-lo, adicionou-se areia.

Figura 5 - (a) Solo da Cidade de Água Branca AL; (b) Teste do vidro.

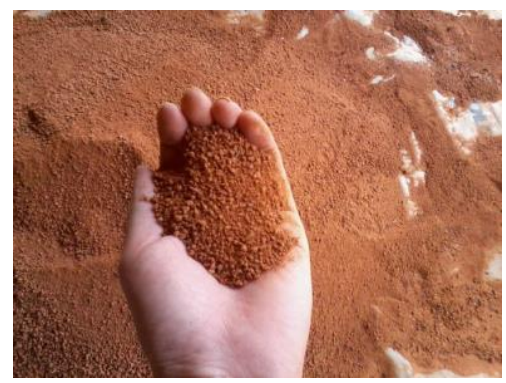

(a)

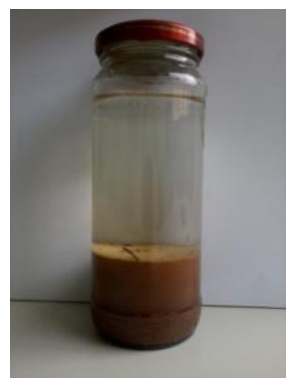

(b)

Fonte: Os autores (2013)

\subsection{Traço e mistura}

Essa etapa é a mais importante na confecção dos tijolos, pois a quantidade do solo sempre deve ser a maior, representando 50\%. Logo, foram adicionados 50\% de solo, $35 \%$ de fibra de papelão e $15 \%$ de areia. 
Para a mistura dos materiais, utilizou-se uma argamassadeira ou um espaço limpo no chão (Figura 6a). Em seguida, a água utilizada foi a mesma adotada para amolecer o papelão e triturá-lo, aproveitando-se o máximo possível dela, evitando desperdício e outros gastos. Ela foi adicionada aos poucos, observando-se a consistência da massa (Figura 6b).

Figura 6 - (a) Mistura dos materiais; (b) Consistência da massa.

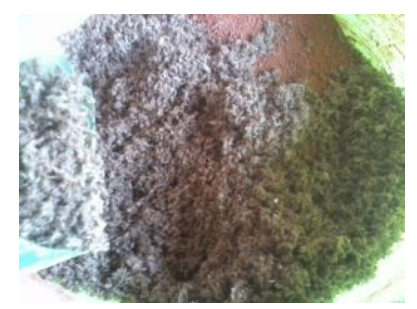

(a)

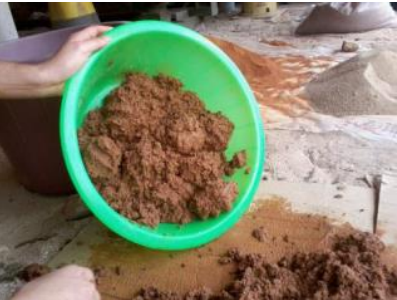

(b)

Fonte: Os autores (2013)

\subsection{Conformação}

Nesta etapa, utilizou-se uma fôrma com dimensões de acordo com a NBR 8491 que especifica as dimensões para tijolos batido de solo e cimento (ABNT, 1984). Sendo assim, utilizou-se uma fôrma de madeira com as dimensões especificadas na norma, incluindo duas alças de apoio para auxiliar a desforma.

É importante frisar que não existe norma específica para os testes em tijolos de adobe. Sendo assim, comparou-se suas dimensões, ao tijolo batido de solo-cimento.

Em seguida, adicionou-se a massa com golpes na fôrma, para que não se formassem bolsas de ar, uma vez que elas prejudicam a resistência do material. Com a fôrma cheia, pressionou-se a massa com as mãos, deixando-a bem compactada. Em seguida, com o auxílio de uma colher de pedreiro, raspou-se a quantidade excedente de massa da borda da fôrma, deixando-a plana, evitando deformações nos tijolos (Figura 7).

Posteriormente, necessitou-se molhar a fôrma para evitar que a massa se fixasse nas paredes, podendo desmanchar o tijolo. Retirou-se a fôrma com as duas mãos para evitar que um lado saísse primeiro do que o outro (Figura $7 \mathrm{~b}$ ). $\mathrm{O}$ tempo de cura desses tijolos é de cerca de 10 dias, mas depende da região, podendo demorar mais alguns dias para secarem. Recomenda-se que os mesmos sequem na sombra, pois a perda de água muito rápida pode ocasionar fissuras e rachaduras comprometendo a resistência (Figura 7c).

Figura 7 - (a) Conformação; (b) Desforma; (c) Cura

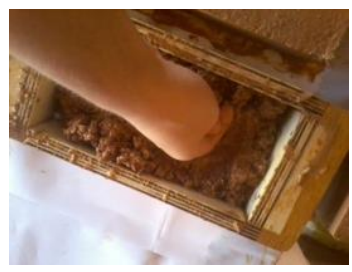

(a)

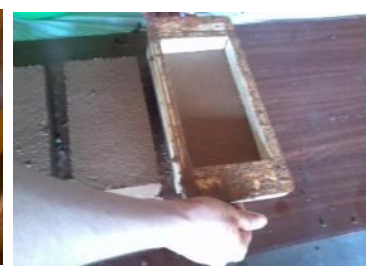

(b)

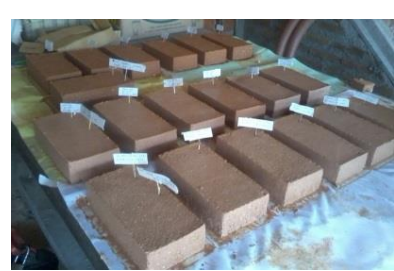

(c)

Fonte: Os autores (2013) 


\section{RESULTADOS}

Os tijolos foram capeados para que a superfície ficasse plana. Para tanto, foi utilizada uma pasta composta por cimento Portland e água, na proporção de $1,5 \mathrm{~kg}$ de cimento e $750 \mathrm{ml}$ de água. Também foi realizado o teste de Absorção de Água (AA), através da equação $A A=\left(\frac{\mathrm{mm}-\mathrm{ms}}{\mathrm{ms}}\right) \cdot 100$, onde $(\mathrm{mm})$ é a massa do bloco molhado e $(\mathrm{ms})$ massa do bloco seco.

O resultado do ensaio de compressão foi comparado com a NBR 15270, Bloco Cerâmico para Alvenaria Estrutural e de Vedação, que determina que os blocos devem suportar uma carga mínima de 1,5 Mpa (ABNT, 2005). Desta forma, para uma melhor distribuição da carga, foram utilizadas duas placas de aço em forma de círculos (Figura 8a), uma na parte superior e outra na parte inferior dos tijolos (Figura 8b), bem como o teste de (AA), também foi comparado com a mesma norma (Figura 8c).

\section{Figura 8 - (a) Teste de compressão; (b) Placas de Aço; (c) Teste de Absorção}

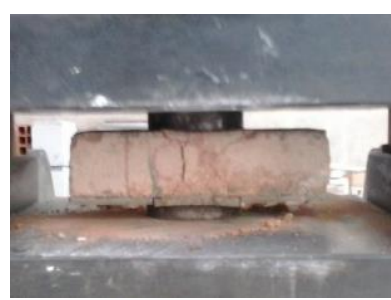

(a)

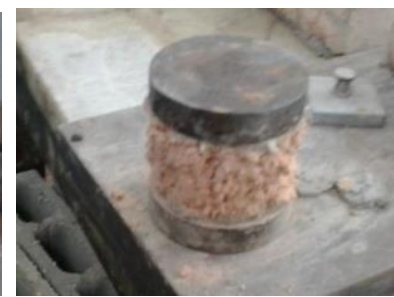

(b)

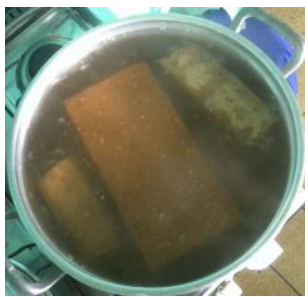

(c)

Fonte: Os autores (2013)

O teste de (AA) não apresentou resultados satisfatórios. A norma especifica que o índice de (AA) fique no intervalo de 8-22 (\%) e os tijolos apresentaram um índice superior a essa percentagem, com 51,3\% de absorção. Para corrigir este problema, os tijolos devem ser melhor compactados, com auxílio de prensas, visando uma melhor junção de suas moléculas e isso pode fazer com que a absorção diminua. Outra alternativa seria a utilização desses tijolos em locais onde há pouca chuva e muita estiagem, a exemplo do semiárido, bem como sua utilização apenas nas paredes internas das edificações.

Entretanto, no que concerne ao teste de resistência, os tijolos conseguiram atingir resultados bastante satisfatórios. Os protótipos de tijolos de adobe com adição de fibras de celulose suportaram uma carga de 1,9 Mpa, ultrapassando o valor mínimo especificado pela NBR 15270. Com esse resultado, o tijolo pode ser utilizado com a mesma função dos blocos cerâmicos para alvenaria. Ademais, observou-se que esse tipo de tijolo é mais leve que os blocos cerâmicos, uma vez que eles pesam em média 1,821 $\mathrm{kg}$ e o tijolo de adobe com as fibras tem um peso médio de $1,103 \mathrm{~kg}$, o que proporciona ao construtor maior rapidez na execução da obra.

\section{CONSIDERAÇÕES FINAIS}

A utilização das fibras de celulose provenientes da reutilização de caixas de papelão demonstra a preocupação com o consumo demasiado de papel e os problemas que a matéria-prima traz ao meio físico-natural. Todavia, a abordagem do uso dessas fibras não pode ser vista apenas como uma contribuição ambiental, uma vez que tais fibras 
melhoram o desempenho mecânico dos tijolos de adobe, conforme pode ser visualizado nos resultados do ensaio de compressão.

Contudo, há de se destacar que os resultados obtidos ainda são parciais, posto que são necessários outros tipos de ensaios, bem como correção dos problemas identificados no teste de absorção. Assim, a pesquisa continua em andamento visando, inclusive, melhorar as propriedades mecânicas desses adobes. A próxima etapa será a confecção de novos adobes compactados em uma prensa manual, a mesma utilizada em tijolos de solo-cimento, de modo a comparar o adobe prensado com aquele feito a mão, observando o desempenho mecânico de ambos. No mais, outras análises sobre os adobes devem fazer parte de estudos futuros, visando melhorar seu desempenho para uma possível aplicação em habitações sociais.

Assim, baseando-se em todo o exposto neste trabalho, infere-se que, numa época onde atenção e o cuidado com o ambiente mobilizam meios de comunicação social e energia dos pesquisadores, a construção com adobes tende a ganhar mais espaço em relação à construção civil no Brasil. Para tanto, é necessária uma maior difusão nas escolas de engenharia e arquitetura, enfatizando a importância de estudos acerca deste material. Além disso, é importante o reconhecimento de suas propriedades físicas e mecânicas por meio da normalização das construções, uma vez que já há em outros países.

\section{REFERÊNCIAS}

ASSOCIAÇÃO BRASILEIRA DE NORMAS TÉCNICAS - ABNT. NBR 8491: Tijolo Maciço de Solo-Cimento. Especificação, São Paulo, 1984.

NBR 15270 - Componentes cerâmicos - Parte 1: Blocos cerâmicos para alvenaria de vedação-Terminologia e requisitos, São Paulo, 2005.

ACHENZA, M.; FENU, L. On Earth stabilization with natural polymers for Earth masonry construction. 2006. Materials and Structures.

ALMEIDA, V. B. Caracterização, análise e perspectivas da matriz energética do setor de papel e celulose. 2013. 80 f. Dissertação (Mestrado em Agroenergia) Fundação Getúlio Vargas, São Paulo, SP.

ASSOCIAÇÃO BRASILEIRA DE CELULOSE E PAPEL (BRACELPA) - Dados do Setor. Janeiro, 2014. Disponível em: $<$ http://www.bracelpa.org.br/bra2/sites/default/files/estatisticas/booklet.pdf $>$. Acesso em: 19 Mar. 2014.

BUSSON, M. A. Krafterra, Desenvolvimento e análise preliminar do desempenho técnico de componentes de terra com a incorporação de fibras de papel kraft provenientes de reciclagem de sacos de cimento para vedação vertical. UNB Faculdade de Arquitetura e Urbanismo, 2009. Tese (Doutorado em Arquitetura e Urbanismo) - Universidade de Brasília 2009.

BOUTH. J. A.C. Estudo da potencialidade da produção de tijolos de adobe misturado com outros materiais - Uma alternativa de baixo custo para a construção civil. 2005. 71 f. Dissertação (Mestrado em Engenharia Mecânica)Universidade Federal do Rio Grande do Norte, Natal, 2005. 
BABOSA, N.P.; GHAVAMI, K. Terra Crua para Edificações. In: ISAIA, G. C. (Ed.). Materiais de Construção Civil e Princípios de Ciência e Engenharia de Materiais. São Paulo: IBRACON, 2010. Cap. 48.

FERRAZ, J. M. G. O papel nosso de cada dia. 2010. Disponível em: $<$ http://www.bdpa.cnptia.embrapa.br/busca?b=pc\&id=881648\&biblioteca=vazio\&busca =autoria:\%22FERRAZ,\%20J.\%20M.\%20G.\%22\&qFacets=autoria:\%22FERRAZ,\%20J .$\% 20$ M.\%20G.\%22\&sort=\&paginacao $=t \&$ paginaAtual=1>. Acesso em: 14 Mai. 2014.

GHAVAMI, K.; FILH, R. D.T.; BARBOSA, N. P. Behaviour of composite soil reinforced with naturalfibres. Cement and Concrete Composites. v.21, p. 39-49, 1999.

INSTITUTO BRASILEIRO DE DEFESA DO CONSUMIDOR (IDEC). O papel e os impactos de sua produção no ambiente. 2006. Disponível em: $<$ http://www.ecolnews.com.br/papel.htm>. Acesso em: 19 Mar. 2014.

IZQUIERDO, I. S. Uso de fibra natural de sisal em blocos de concreto par alvenaria estrutural. 2011. 146 f. Dissertação (Mestrado em Engenharia de Estruturas) - Escola de Engenharia de São Carlos, Universidade de São Paulo, São Carlos, 2011.

JOHN, V.M. Materiais de Construção e o Meio Ambiente. In: ISAIA, G. C. (Ed.). Materiais de Construção Civil e Princípios de Ciência e Engenharia de Materiais. São Paulo: IBRACON, 2010. Cap. 49.

NEVES, C. M.; FARIA, O. B.; ROTONARO, R.; et al. Seleção de solos e métodos de controle em construção com terra - Práticas de Campo. 2005. Projeto de investigação, Proterra.

PÓLIS. Coleta Seletiva de Lixo - Reciclando Materiais e Reciclando Valores. 1998.

PLANO NACIONAL DOS RESÍDUOS SÓLIDOS. Versão preliminar para consulta. Disponível em: $<$ http://www.mma.gov.br/estruturas/253/_publicacao/253_publicacao02022012041757. pdf $>$. Acesso em: 13 Maio 2014.

SENHORAS, E. M. Estratégias de uma Agenda para a Cadeia agroindustrial do Coco: Transformando a Ameaça dos Resíduos em Oportunidades Eco-Eficientes. Monografia, 36p. 2003. Campinas - SP

SÉRIE PRODUTOR RURAL. Como produzir tijolo sem queimas reforçados com fibras de bananeira. 1998. Universidade de São Paulo. Escola Superior de Agricultura "Luiz de Queiroz" - $\quad$ ESALQ. Disponível em: $<$ http://www.esalq.usp.br/biblioteca/PUBLICACAO/SP11/>. Acesso em: 06 Mai. 2014.

VARUM, H.; COSTA, H.; PEREIRA, H. Caracterização do Comportamento Estrutural de Paredes de Alvenaria de Adobe. Revista da Associação Portuguesa de Análises Experimentais de Tensões. V.15, p. 23-32, Universidade de Aveiro. Departamento de Engenharia civil. 2008.

WEB-RESOL. Curiosidades. $2009 . \quad$ Disponível em: $<$ http://www.resol.com.br/site/curiosidades2.php?id=3018\#.U1gO1PldWS8>. Acesso em: 14 Mai. 2014. 